\title{
Acetaminophen reduces the protein levels of high affinity amino acid permeases and causes tryptophan depletion
}

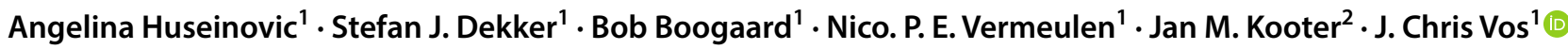

Received: 17 November 2017 / Accepted: 28 June 2018 / Published online: 5 July 2018

(c) The Author(s) 2018

\begin{abstract}
In yeast, toxicity of acetaminophen (APAP), a frequently used analgesic and antipyretic drug, depends on ubiquitin-controlled processes. Previously, we showed a remarkable overlap in toxicity profiles between APAP and tyrosine, and a similarity with drugs like rapamycin and quinine, which induce degradation of the amino acid permease Tat2. Therefore, we investigated in yeast whether APAP reduced the expression levels of amino acid permeases. The protein levels of Tat2, Tat1, Mup1 and Hip1 were reduced, while the expression of the general permease Gap1 was increased, consistent with a nutrient starvation response. Overexpression of Tat1 and Tat2, but not Mup1, Hip1 and Gap1 conferred resistance to APAP. A tryptophan auxotrophic strain trpls was more sensitive to APAP than wild-type and addition of tryptophan completely restored the growth restriction of trpl $1 \Delta$ upon APAP exposure, while tyrosine had an additive effect on APAP toxicity. Furthermore, intracellular aromatic amino acid concentrations were reduced upon APAP exposure. This effect was less prominent in ubiquitin-deficient yeast strains that were APAP resistant and showed a reduced degradation of high affinity amino acid permeases. APAP-induced changes in intracellular amino acid concentrations were also detected in hepatoma HepG2 cells indicating significance for humans.
\end{abstract}

Keywords Acetaminophen $\cdot$ Tryptophan $\cdot$ Tyrosine $\cdot$ Nutrient starvation $\cdot$ Amino acid permeases

\section{Introduction}

Acetaminophen ( $N$-acetyl-p-aminophenol, paracetamol, APAP), a widely used analgesic and antipyretic, is considered safe at therapeutic doses. However, an overdose induces hepatotoxicity and is one of the major causes of acute liver failure in the USA and Western Europe (Bernal et al. 2010).

Handling Editor: C. Schiene-Fischer.

Electronic supplementary material The online version of this article (https://doi.org/10.1007/s00726-018-2613-8) contains supplementary material, which is available to authorized users.

J. Chris Vos

j.c.vos@vu.nl

1 AIMMS, Division of Molecular Toxicology, Department of Chemistry and Pharmaceutical Sciences, VU University Amsterdam, De Boelelaan 1083, 1081 HZ Amsterdam, The Netherlands

2 AIMMS, Department of Molecular Cell Biology, Section Genetics, VU University Amsterdam, De Boelelaan 1083, 1081 HZ Amsterdam, The Netherlands
APAP can also cause toxicity at therapeutic doses as seen in Stevens-Johnsons syndrome and toxic epidermal necrolysis (Khawaja et al. 2012; Kim et al. 2014). Several studies reported a link between APAP use during pregnancy and the incidence of attention deficit hyperactivity disorder and hyperkinetic disorder in children (Liew et al. 2014), and long-term use was associated with increased incidence of cancer (Walter et al. 2011b, b) and asthma (Henderson and Shaheen 2013). Risk factors for APAP toxicity are concurrent medications, poor nutritional status, chronic alcohol abuse, obesity and non-alcoholic fatty liver disease (Larson et al. 2005; Michaut et al. 2014).

The major cause of APAP-induced hepatotoxicity and acute liver failure is due to the formation of the reactive metabolite $N$-acetyl-p-benzoquinone imine (NAPQI) by cytochrome $\mathrm{P} 450$, which binds to glutathione causing glutathione depletion and liver damage (Bessems and Vermeulen 2001; James et al. 2003). However, APAP can also be toxic without formation of NAPQI, as has been shown in mammalian cells (Jensen et al. 1996) and yeast (Srikanth et al. 2005). Furthermore, toxicity was also observed before 
glutathione depletion occurs (Shuhendler et al. 2014; Miettinen and Björklund 2014).

Previously, we used yeast Saccharomyces cerevisiae as a eukaryotic model organism to get more insight into NAPQI independent APAP toxicity, because yeast lacks the genes coding for drug-metabolizing P450 enzymes and is incapable of APAP metabolism and formation of NAPQI (Srikanth et al. 2005). Our study revealed that APAP toxicity depends on the cellular concentration of ubiquitin: ubiquitin depletion confers resistance to APAP, whereas ubiquitin overexpression caused sensitivity (Huseinovic et al. 2017b). Based on the correlation between ubiquitin levels and APAP-induced toxicity, we also performed a deubiquitinase (DUB) gene deletion screen (Huseinovic et al. 2017a). DUBs are enzymes that can reverse the process of ubiquitination, that often regulate ubiquitin levels and are involved in regulation of many essential cellular pathways such as DNA damage repair, internalization of membrane proteins, cell division and stress (Finley et al. 2012). The DUB screen showed that the APAP sensitivity and resistance growth phenotypes of the DUB deletion strains resembled those caused by other drugs, such as quinine (Khozoie et al. 2009), rapamycin (Beck et al. 1999), FTY720 (Welsch et al. 2003), FK506 (Schmidt et al. 1994) and ibuprofen (He et al. 2014). The latter drugs also induce tryptophan starvation by the ubiquitin-dependent degradation of the Tat 2 amino acid permease (AAP).

Uptake of extracellular amino acids is regulated by high and low affinity AAPs (Regenberg et al. 1999; Ljungdahl and Daignan-Fornier 2012), whose expression in yeast is regulated by the amino acid sensing SPS and TOR pathways (Ljungdahl 2009; Shin et al. 2009). Membrane protein levels are regulated by the ubiquitin ligase Rsp5 followed by internalization from the plasma membrane and vacuolar degradation (Nikko and Pelham 2009). The internalization can be induced by a variety of environmental conditions, such as nutrient starvation (Khozoie et al. 2009), nutrient excess (Nikko and Pelham 2009), inhibition of the TOR pathway (Beck et al. 1999) or exposure to high pressure (Miura and Abe 2004). A variety of drugs have been identified that induce degradation of the high affinity permease Tat2, selective for aromatic amino acids. For example, quinine blocks tryptophan uptake through competitive inhibition, as it is structurally similar to tryptophan, and rapamycin causes tryptophan starvation indirectly by inhibiting the TOR pathway. During nutrient starvation, all high affinity AAPs are degraded, including Tat1 and Hip1, while the general AAP Gap1 is upregulated (Beck et al. 1999), regardless of the initial cause of the starvation response.

Since APAP treatment might result in aberrant amino acid sensing similar to an excess of tyrosine (Huseinovic et al. 2017a), we studied whether APAP can induce degradation of high affinity AAPs and increase the expression of general
AAP Gap1, reminiscent of a nutrient starvation response. Also, we investigated the APAP-induced changes in intracellular amino acid concentrations.

\section{Materials and methods}

\section{Yeast strains and media}

Haploid deletion strains of $S$. cerevisiae with a BY4741

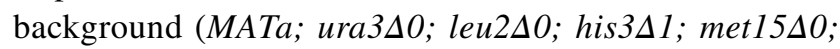
gene $\Delta::$ kanMX4) and BY4733 (MATa; ura $3 \Delta 0$; leu $2 \Delta 0$; his $3 \Delta 200$; met $15 \Delta 0$; trp $1 \Delta 63$; gene $\Delta:: k a n M X 4)$ were obtained from EUROSCARF (Frankfurt, Germany). YPD medium contained $1 \%$ yeast extract, $2 \%$ peptone and $2 \%$ glucose. Selective YNB-URA medium contained $0.67 \%$ yeast nitrogen base, $2 \%$ glucose, $2 \%$ agar, $20 \mathrm{mg} / \mathrm{l}$ adenine (Ade), $20 \mathrm{mg} / \mathrm{l}$ uracil (Ura) and amino acids: $20 \mathrm{mg} / \mathrm{l}$ arginine (Arg), $20 \mathrm{mg} / \mathrm{l} \mathrm{histidine} \mathrm{(His),} 60 \mathrm{mg} / \mathrm{l}$ leucine (Leu), $30 \mathrm{mg} / 1$ lysine (Lys), $20 \mathrm{mg} / \mathrm{l}$ methionine (Met), $50 \mathrm{mg} / \mathrm{l}$ phenylalanine (Phe), $200 \mathrm{mg} / \mathrm{l}$ threonine (Thr), $20 \mathrm{mg} / \mathrm{l}$ tryptophan (Trp), and $30 \mathrm{mg} / \mathrm{l}$ tyrosine (Tyr). Plates contained additionally $2 \%$ agar. Yeast extract and peptone were obtained from Melford Laboratories Ltd. (Ipswich, UK). Amino acids, yeast nitrogen base, agar and glucose were purchased from Sigma-Aldrich, St. Louis, USA.

\section{Plasmids and transformations}

PCR amplifications of genes TAT1, MUP1, HIPl and GAPl were made using genomic DNA of BY4741 strains as template. The genes with an N-terminal HA-tag were cloned in two steps. First, PCR amplification of the gene coding region, without start codon and containing stop codon plus $\sim 300$ bp downstream sequence, was cloned into a Yeplac 195 based plasmid $(2 \mu, U R A 3)$ containing a $3 \times$ HA tag (kindly provided by Jan Paul Bebelman). Subsequently, the gene-specific promoter, $\sim 1000 \mathrm{bp}$ sequence upstream of the coding region, was cloned upstream of the HA-tagged coding region. The clones were identified by restriction digestion and additionally sequenced to verify the correct DNA sequence. The primers sequences are available on request. The plasmids YEplac195 $(2 \mu, U R A 3)$ containing HA-tagged versions of TAT2 and TAT2 ${ }^{5 K>R}$ genes and YCpac33 (CEN, URA3) containing HA-tagged version of TAT2 were a kind gift from Prof. M. Hall. The plasmids were transformed into yeast cells by the freeze-thaw method as previously described (Klebe et al. 1983).

\section{Western blotting}

For the determination of HA-tagged protein levels from multi copy plasmids $(2 \mu, U R A 3)$, overnight cultures (16 h) 
were grown at $30{ }^{\circ} \mathrm{C}$ in YNB-URA medium to $\mathrm{OD}_{600}$ of 0.5 in $10 \mathrm{ml} \mathrm{YNB}$ for each sample. Prior to APAP exposure, the cultures were incubated at $37^{\circ} \mathrm{C}$ for $3 \mathrm{~h}$. Subsequently, the cells were treated with 0, 50, 75 and $100 \mathrm{mM}$ APAP (SigmaAldrich, St. Louis, USA) for $1 \mathrm{~h}$. The $\mathrm{OD}_{600}$ was measured and for each sample the volume of cells equivalent to $\mathrm{OD}_{600}$ of 10 was harvested by centrifugation and were frozen at $-20{ }^{\circ} \mathrm{C}$. The cell pellets were dissolved in $200 \mu \mathrm{L}$ Laemmli buffer without bromophenol blue $(50 \mathrm{mM}$ Tris- $\mathrm{HCl} \mathrm{pH} 6.8$, $2 \%$ SDS, $10 \%$ glycerol, 12.5 mM EDTA, supplemented with $1 \mathrm{mM}$ PMSF, $10 \mathrm{mM}$ DTT and protease inhibitor (EDTAfree Complete, Roche) and cells were mechanically broken by vortexing with acid washed beads (Sigma-Aldrich) for $6 \mathrm{~min}$. Subsequently, the lysates were incubated at $37^{\circ} \mathrm{C}$ for $10 \mathrm{~min}$ and the protein extract was separated from insoluble cell debris and beads by centrifugation. Aliquots were diluted 1:40 in water and the amount of total protein was determined by a protein assay (Bio-Rad). Subsequently, $0.02 \%$ bromophenol blue was added to the samples and a Western blot was performed. Briefly, equal amounts of protein were loaded on $10 \%$ bis-Tris gels and the proteins were separated in MES buffer (Life technologies).

For the determination of HA-Tat2 expression from a single copy plasmid (CEN, URA3), the cells were grown and treated with APAP as described above and P13 membrane fractions were isolated as described previously (Abe and Iida 2003). Briefly, the cells were washed with $10 \mathrm{mM}$ $\mathrm{NaN} 3 / 10 \mathrm{mM} \mathrm{NaF}$ and lysis buffer $(50 \mathrm{mM}$ Tris-HCl, 5 mMEDTA, $10 \mathrm{mM} \mathrm{NaN3}, 1 \mathrm{mM}$ PMSF and protease inhibitor (EDTA-free Complete, Roche). After washing, the cells were resuspended in $200 \mu \mathrm{l}$ lysis buffer and broken with glass beads (vortexed for $6 \mathrm{~min}$ ) and centrifuged for $2 \mathrm{~min}$ at $300 \mathrm{~g}$ to remove unbroken cells and debris. Then, $100 \mu \mathrm{l}$ of the cleared lysates was mixed with an equal volume of STE20 buffer (20\% sucrose, $50 \mathrm{mM}$ Tris- $\mathrm{HCl} \mathrm{pH} \mathrm{7.5,} 5 \mathrm{mM}$ EDTA) and centrifugated at $13,000 \mathrm{~g}$ for $10 \mathrm{~min}$ to yield a P13 (pellet) fraction. P13 fractions were resuspended in $30 \mu$ of adjusted $1 \times$ Laemmli sample buffer $(60 \mathrm{mM}$ Tris- $\mathrm{HCl} \mathrm{pH} \mathrm{6.8,} \mathrm{5 \%} \mathrm{SDS,} 10 \%$ glycerol and 5\% ß-mercaptoethanol) at $37^{\circ} \mathrm{C}$ for $10 \mathrm{~min}$. The protein concentration was measured by nanodrop before $0.004 \%$ bromophenol blue was added. Equal amounts of protein $(\sim 120 \mu \mathrm{g})$ were loaded on $12 \%$ Tris- $\mathrm{HCl}$ gels and the proteins were separated in Tris-Glycine-SDS buffer. The proteins were blotted on a $0.45 \mu \mathrm{m}$ PVDF membrane (Thermo scientific). Protein loading was controlled by Ponceau $\mathrm{S}$ staining. The membrane was blocked in 5\% skimmed milk (Sigma-Aldrich, St. Louis, USA) resolved in TBST ( $20 \mathrm{mM}$ Tris, $150 \mathrm{mM} \mathrm{NaCL}, 0.1 \%$ Tween 20) and washed in TBST. HRP conjugated HAantibody and anti-actin antibody used for detection were obtained from Santa Cruz (sc-8017) and Merck Millipore (MAB1501), respectively. The secondary antibodies rabbit anti-mouse HRP conjugated used for actin detection was ordered from Abcam (ab97046). The detection was performed by ECL reaction (Pierce) in a Bio-Rad imager.

\section{Spot dilution assay}

For the AAPs overexpression experiments, WT cells were transformed with plasmids $(2 \mu, U R A 3)$ of the HA-tagged genes of Tat2, Tat1, Hip1, Mup1 and Gap1 and grown overnight in YNB-URA medium at $30^{\circ} \mathrm{C}$. Subsequently, cultures were diluted to an $\mathrm{OD}_{600}$ of 0.05 and additional fivefold serial dilutions were made. The cells were plated on YPD plates with and without $70 \mathrm{mM}$ APAP and incubated for 3 days at $37^{\circ} \mathrm{C}$. For the $\operatorname{trp} 1 \Delta$ sensitivity determination, WT (BY4741) and trpl $\Delta$ (BY4733) cells were grown overnight in YPD medium at $30^{\circ} \mathrm{C}$ and fivefold serial dilutions of cell suspensions with optical density $\mathrm{OD}_{600}$ of 0.05 were made and plated on YPD plates with or without $50 \mathrm{mM}$ APAP or $200 \mathrm{ng} / \mathrm{ml}$ rapamycin (Sigma-Aldrich, St. Louis, USA) and incubated for 3 days at $37^{\circ} \mathrm{C}$. The cells were spotted on YPD agar plates using a 96-well replica plater (Sigma-Aldrich).

\section{Growth rate measurements}

The yeast cells were grown at $30{ }^{\circ} \mathrm{C}$ in YPD medium to exponential growth phase, washed in water and resuspended in YNB medium with predefined amino acid concentrations (see the composition of YNB medium). The treatments were performed in duplicate in a 96-well plate in a final volume of $200 \mu \mathrm{l}$ in medium containing $40 \mathrm{mM}$ APAP and additional onefold of different amino acids. The cells were grown for $19 \mathrm{~h}$ at $37{ }^{\circ} \mathrm{C}$ and the $\mathrm{OD}_{600}$ was measured every $20 \mathrm{~min}$. The controls were cells grown in medium with or without $40 \mathrm{mM}$ APAP. The average growth curves and standard errors of the two duplicates were calculated.

\section{Yeast cells sample preparation for HPLC}

$\mathrm{WT}, u b i 4 \Delta$, doa $4 \Delta$ and doal $\Delta$ yeast cells were grown in duplicate in $5 \mathrm{ml}$ YPD medium overnight at $30^{\circ} \mathrm{C}$. Subsequently, the $\mathrm{OD}_{600}$ was measured and the cultures were diluted in fresh YPD medium to $\mathrm{OD}_{600}$ of 0.5 to a final volume of $20 \mathrm{ml}$ and pre-incubated for $3 \mathrm{~h}$ at $37{ }^{\circ} \mathrm{C}$ to reach exponential phase. For the drug treatments, each culture was separated in two $10 \mathrm{ml}$ cultures and, subsequently, $10 \mathrm{ml}$ of pre-warmed YPD medium with or without $150 \mathrm{mM}$ APAP was added to the final concentration of 0 and $75 \mathrm{mM}$ APAP. The cells were incubated $37^{\circ} \mathrm{C}$; WT cells for 10,30 and 60 min and $u b i 4 \Delta$, $d o a 4 \Delta$ and $d o a l \Delta$ for $60 \mathrm{~min}$. Subsequently, the cultures were cooled on ice and washed twice in ice-cold milliQ water. After washing, the cells were resuspended in $1.1 \mathrm{ml}$ ice-cold milliQ water, $1 \mathrm{ml}$ was centrifuged at $2000 \mathrm{~g}$ for $2 \mathrm{~min}$ and the pellets were frozen at $-20{ }^{\circ} \mathrm{C}$. The remaining $100 \mu \mathrm{l}$ was used to measure $\mathrm{OD}_{600}$ and this value was used to resuspend the 
frozen pellets in appropriate amount of milliQ water containing $100 \mu \mathrm{M}$ of DL-2-aminobutyric acid (TCI, Tokyo, Japan) as internal standard to obtain a cell density of $\mathrm{OD}_{600}$ is 8 per $1 \mathrm{ml}$. Subsequently, the cell suspension was incubated at $90{ }^{\circ} \mathrm{C}$ for $15 \mathrm{~min}$ and centrifuged for $2 \mathrm{~min}$. The supernatant containing free amino acids was collected and filtered through a small volume $0.2 \mu \mathrm{m}$ filter (purchased by Phenomenex) and further prepared for HPLC analysis by diethyl ethoxymethylenemalonate (DEEMM) derivatization.

\section{HepG2 cells sample preparation for HPLC}

HepG2 cells were cultured in Dulbecco's Modified Eagle's Medium (DMEM; Lonza, Basel, Switzerland) supplemented with $10 \%$ Fetal Bovine Serum (FBS) (Lonza), 1\% penicillin/streptomycin (Lonza), 1\% L-glutamine (Lonza) and 1\% non-essential amino acids (Sigma-Aldrich). During routine passage, $80 \%$ confluent cells were washed with phosphatebuffered saline (PBS) solution (Lonza), trypsinized with Trypsin-EDTA (Lonza). Prior to APAP treatment, $1 \times 10^{6}$ HepG2 cells/well in a 6-well plate were seeded and grown at $37{ }^{\circ} \mathrm{C}$ in a monolayer to the confluency of $\sim 70 \%$. Subsequently, the cells were washed with PBS and DMEM medium with $10 \%$ FBS containing 0, 10 and $20 \mathrm{mM}$ APAP and incubated for $2 \mathrm{~h}$. The medium was removed by aspiration and the cells were washed two times with warm PBS solution. Subsequently, $500 \mu \mathrm{l}$ water containing $100 \mu \mathrm{M}$ DL-2-aminobutyric acid (internal standard) was added in each well, the cells were harvested by scraping, incubated at $90{ }^{\circ} \mathrm{C}$ for $15 \mathrm{~min}$, vortexed and centrifuged at high speed for $15 \mathrm{~min}$. The supernatant containing released free intracellular amino acids was collected, filtered through a $0.2 \mu \mathrm{m}$ filter and prepared for HPLC by DEEMM derivatization.

\section{Amino acid DEEMM derivatization and HPLC measurements}

The amino acid derivatization was performed according to (Alaiz et al. 1992). Briefly, $400 \mu \mathrm{l}$ of the amino acid extract obtained from yeast of HepG2 cells was mixed with $1 \mathrm{ml}$ of $150 \mathrm{mM}$ borate buffer $\mathrm{pH} 9.0$ and $0.8 \mu \mathrm{L}$ DEEMM (SigmaAldrich, St. Louis, USA) and subsequently incubated at $50{ }^{\circ} \mathrm{C}$ for $1 \mathrm{~h}$ by shaking at $1400 \mathrm{rpm}$. The samples were centrifuged for $15 \mathrm{~min}$ at $20,800 \mathrm{~g} .50 \mu \mathrm{l}$ of the samples were injected by a Gilson 234 auto injector connected to two Gilson 305 pumps onto a $250 \times 4.8 \mathrm{~mm}$ Zorbax column connected to a C18 guard column. The UV signal at $280 \mathrm{~nm}$ was detected with a photodiode array detector (SPD-20A Shimadzu). Eluent $A$ was $10 \mathrm{mM}$ acetate $\mathrm{pH} 5.8$ in $\mathrm{ddH}_{2} \mathrm{O}$ and eluent $B$ was $100 \%$ acetonitrile. The flow rate was set to $0.9 \mathrm{ml} / \mathrm{min}$. The HPLC program was optimized to obtain an optimal amino acid peak separation by adjusting the eluent $B$ percentage (\%) at different time points (Table 1).

\section{HPLC data analysis and statistics}

The obtained HPLC chromatograms were analyzed with Shimadzu CLASS-VP Chromatography Data System 4.3 software (Kyoto, Japan), which quantified each area peak for each amino acid with and without APAP treatment and the values were exported in an excel file. The amino acid retention times were determined by HPLC analysis of each individual amino acid standards, which were derivatized the same way as the samples. The peak area values were normalized against the values of the internal standard DL-2-aminobuttylic acid. The relative increase or decrease for each amino acid with APAP treatment was calculated from the average of the duplicate measurements according to the formula $R=\frac{(X-Y)}{Y}=\frac{X}{Y}-1[\%]$. The standard error was calculated according to the general rule for error calculation of multiplication or division of measured quantities with formula $\delta R=|R| \cdot \sqrt{\left(\frac{\delta X}{X}\right)^{2}+\left(\frac{\delta Y}{Y}\right)^{2}}$, where $X$ and $Y$ are the average values with and without APAP treatment, respectively, $\delta X$ and $\delta Y$ are their corresponding standard deviations, and $R$ is the relative increase or decrease percentage when compared to the non-treated cells.

\section{Results}

\section{APAP induces degradation of Tat2, Tat1, Mup1 and Hip1, and upregulates Gap1}

In the previously performed DUB toxicity screen (Huseinovic et al. 2017a), we showed similarities between the DUB toxicity profiles of tyrosine, APAP and drugs causing degradation of Tat2, such as quinine (Khozoie et al. 2009) and ibuprofen (He et al. 2014). To determine whether APAP can also induce degradation of amino acid permeases, we tested the expression levels of several high affinity AAPs during APAP treatment at concentrations that reduce the growth rate. We used for this WT cells transformed with plasmids $(2 \mu, U R A 3)$ expressing HA-tagged versions of Tat2 (Trp, Tyr and Phe permease), Tat1 (Trp, Tyr, Leu, Val and Thr permease), Hip1 (His permease), Mup1 (Met permease) and of the general AAP Gap1. The cells were grown for $1 \mathrm{~h}$ in YNB-URA medium containing 0, 50,
Table 1 HPLC program used for amino acids determination

\begin{tabular}{|c|c|c|c|c|c|c|c|c|c|c|c|}
\hline Time point (min) & 0 & 10 & 20 & 30 & 40 & 45 & 56 & 58 & 60 & 61 & 72 \\
\hline Eluent $B(\%)$ & 1 & 5 & 9 & 13 & 18 & 19 & 30 & 50 & 60 & 95 & 1 \\
\hline
\end{tabular}


75 and $100 \mathrm{mM}$ of APAP and protein levels were determined by Western blotting. The results showed that the abundance of Tat2, Tat1, Hip1 and Mup1 declined in a dose-dependent manner upon APAP exposure (Fig. 1). In contrast, Gap1 levels increased in a dose-dependent manner. A similar effect of Tat2 degradation upon APAP exposure is also shown in WT cells expressing HA-TAT2 from a single copy plasmid (CEN, URA3) (Fig. 1, bottom panel), indicating that the observed effect is not restricted to overexpression conditions. Concurrent high affinity AAPs degradation and induction of general AAP Gap1 suggest that APAP caused a nutrient starvation response.

\section{Tat 2 and Tat 1 overexpression confers resistance to APAP}

APAP induced degradation of high affinity AAPs Tat1, Tat2, Hip1, Mup1, which was likely to limit amino acid availability in the cell. Therefore, we wanted to see whether the overexpression of these permeases could counteract the APAPinduced growth reduction. For that purpose, we expressed the permeases in WT cells from a multicopy plasmid using a HA N-terminal tag, which has been used successfully before (Beck et al. 1999). We tested these cells in a spot dilution assay with and without APAP. Interestingly, only Tat 1 and Tat 2 overexpression, which are both involved in uptake of Trp and Tyr, conferred APAP resistance, while overexpression of Hip1 (His uptake), Mup1 (Met uptake) and Gap1 (general amino acid permease) did not rescue the cell growth upon APAP exposure (Fig. 2a). In our previous research
(Huseinovic et al. 2017a) we already showed that addition of extra Trp provided growth rescue upon APAP exposure. Therefore, we wanted to see whether a Trp auxotrophic strain would be sensitive to APAP. Indeed, the Trp auxotrophic strain BY4733 was hypersensitive to APAP when compared to its TRP1 counterpart BY4741 (WT). Rapamycin caused a similar sensitivity and has been shown to induce Trp starvation and Tat 1 and Tat 2 degradation through the inhibition of TOR pathway (18) (Fig. 2b).

\section{Tat2 expression level is stabilized in APAP resistant strains ubi4 $\Delta$, ubp $6 \Delta$ and doa $1 \Delta$}

In our previous research (Huseinovic et al. 2017a, b), we showed that APAP toxicity depends on cellular ubiquitin levels and that ubiquitin-deficient strains, such as $u b i 4 \Delta$, doa $1 \Delta$, doa $4 \Delta, u b p 6 \Delta$ and $\Delta u b p 14$, conferred resistance to APAP (Huseinovic et al. 2017b). Since it is known that the Tat 2 expression level is stabilized in deletion strains doa $4 \Delta, u b p 6 \Delta$ and $u b p 14 \Delta$ under high pressure (Miura and Abe 2004), and based on our current finding that only Tat 1 or Tat 2 overexpression conferred resistance to APAP, we hypothesized that the Tat 2 expression level is stabilized in the APAP resistant mutants during APAP treatment. To determine the levels of Tat 2 upon APAP treatment, we expressed a HA-tagged TAT2 in WT, ubi4 4 , ubp $6 \Delta$ and doal $\Delta$ cells and determined its abundance after $1 \mathrm{~h}$ exposure to APAP. We also tested the expression of HATat $2^{5 K>R}$ mutant in WT cells, which lacks five lysines and cannot be ubiquitinated (Beck et al. 1999). The role protein

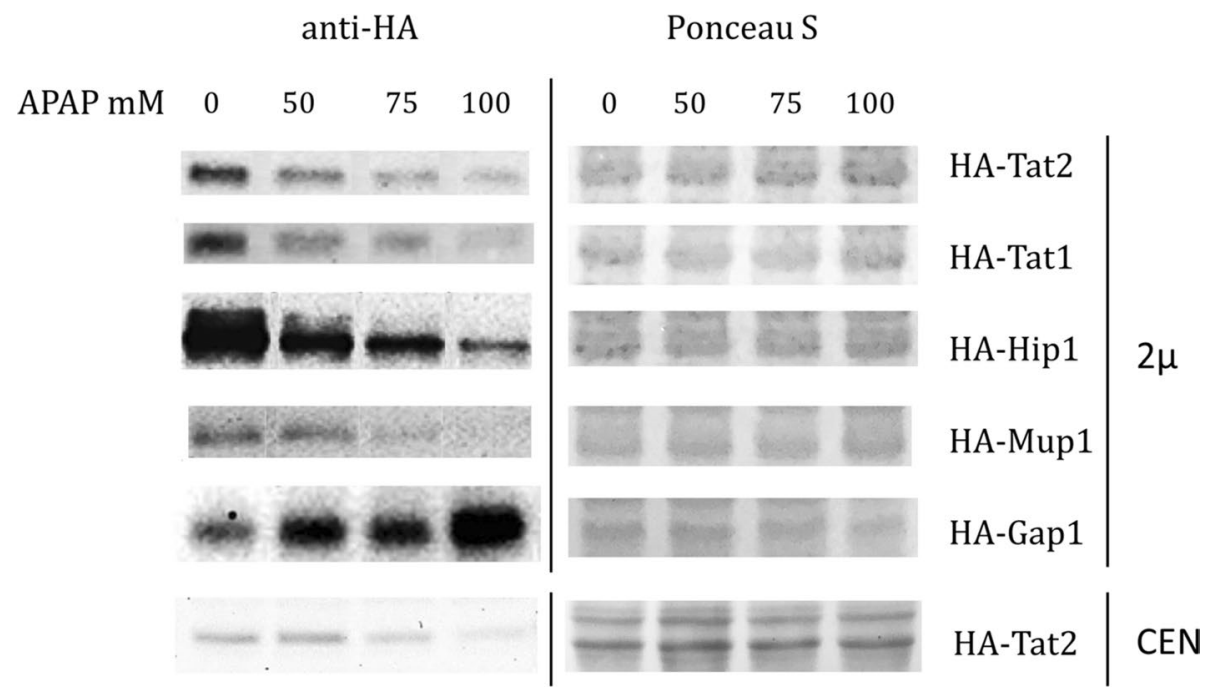

Fig. 1 APAP induced concentration-dependent degradation of Tat2, Tat1, Hip1 and Mup1, while Gap1 expression was increased. The WT cells containing a multi copy plasmid $(2 \mu, U R A 3)$ or a single copy plasmid (CEN, URA3) with corresponding HA-tagged genes were grown exponentially in YNB-URA and treated with $0,50,75$ and $100 \mathrm{mM}$ APAP for $1 \mathrm{~h}$. Equal amounts of protein were loaded. The blots were assayed for HA-Tat2, HA-Tat1, HA-Hip1, HA-Mup1 and HA-Gap1 expression (on the left) and the Ponceau $S$ staining was used as the loading control (on the right) 


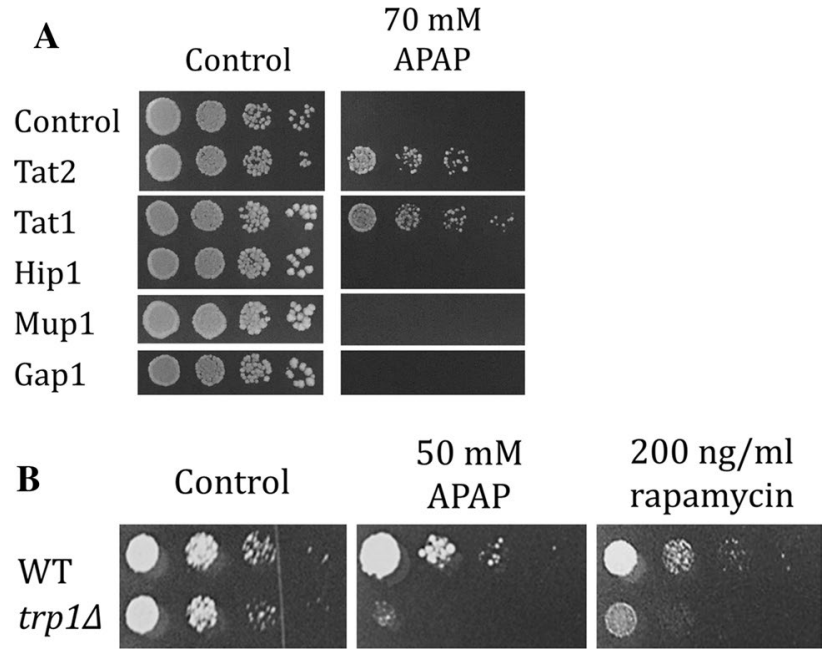

Fig. 2 Tat2 and Tat 1 overexpression confers APAP resistance and a $\operatorname{trp} 1 \Delta$ strain is hypersensitive. a WT cells were transformed with the plasmid $(2 \mu$, URA3) containing the HA-tagged gene of Tat2, Tat1, Hip1, Mup1 and Gap1. The cells were grown overnight in YNB-URA medium and fivefold serial dilutions of cell suspensions with optical density $\mathrm{OD}_{600}$ of 0.05 were plated on YPD plates containing 0 and $70 \mathrm{mM}$ APAP and incubated for 3 days at $37^{\circ} \mathrm{C}$. b WT (BY4741) and $\operatorname{trp} 1 \Delta$ (BY4733) cells were grown overnight in YPD medium and fivefold serial dilutions of cell suspensions with optical density $\mathrm{OD}_{600}$ of 0.05 were plated on YPD plates containing $50 \mathrm{mM}$ APAP and $200 \mathrm{ng} / \mathrm{ml}$ rapamycin. The plates were incubated for 3 days at $37^{\circ} \mathrm{C}$

ubiquitination by E3 ubiquitin ligase Rsp5 in protein degradation of AAPs (i.e. Mup1, Tat1 and Tat2) has been wellestablished (Nikko and Pelham 2009; Suzuki et al. 2013). Indeed, the Western blot results revealed that the levels of Tat 2 were unaffected and higher in $u b i 4 \Delta$, doal $\Delta$ and ubp6 6 strains when compared to the WT, probably due to the reduced levels of ubiquitin and/or reduced vacuolar degradation of transmembrane proteins (doal $\Delta$ ). Similarly, the amount of HA-Tat $2^{5 K>R}$ mutant was also constant upon APAP exposure, demonstrating the role of ubiquitination in Tat2 degradation. The apparent higher levels of Tat 2 expression in the deletion strains under normal conditions may also be due to the reduced ubiquitin levels in the cell (Fig. 3).

\section{The effects of individual amino acids on APAP-induced growth inhibition}

Because Tat 1 and Tat 2 overexpression conferred APAP resistance and a $\operatorname{trp} 1 \Delta$-strain was more sensitive to APAP, we investigated the effect of addition of individual amino acids on growth of WT and trpl $\Delta$ cells during APAP exposure. We tested the growth effect of addition of a surplus of the aromatic amino acids Trp and Tyr (transported by Tat1 and Tat2) and Phe (transported by Tat2). We also tested addition of His, Met or Leu, since WT and trpl $\Delta$ cells are auxotrophic for these amino acids, and their transporters (Hip1, Mup1 and Tat1, respectively) were downregulated during APAP exposure (Fig. 1). For comparison and as a control, we also tested the growth effects of Arg and Lys (transported by Lyp1), Glu (transported by Gap1) and Thr (transported by Agp1, Gnp1 and Tat1). The cells were grown in 96-well plates in liquid YNB medium containing APAP with or without onefold extra addition of each amino acid based on the concentrations that are normally present in YNB medium (see Materials and methods) and the cell growth was measured as an increase in optical density $\left(\mathrm{OD}_{600}\right)$ (Fig. 4). Note that onefold extra addition of

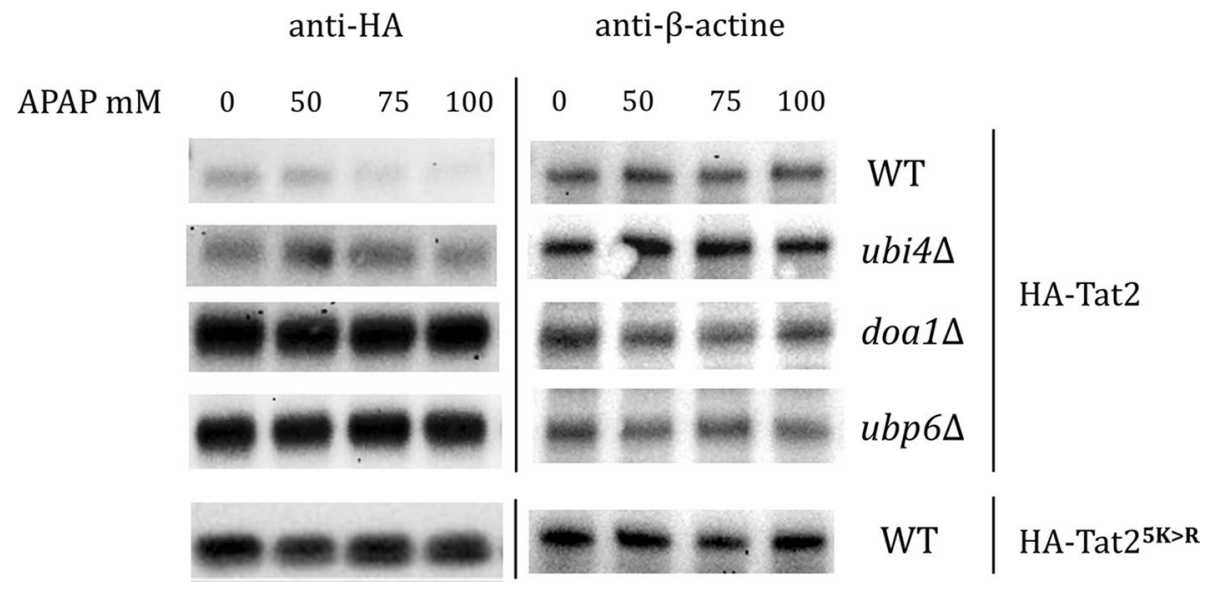

Fig. 3 APAP induces degradation of Tat2. APAP treatment induced degradation of Tat2 in WT cells, while the expression level of Tat 2 was unaffected in ubiquitin-deficient strains $u b i 4 \Delta$, doal $\Delta$ and $u b p 6 \Delta$. The expression level of $T A T 2^{5 K>R}$ mutant was also constant in WT cells. The cells containing multi copy plasmid $(2 \mu, U R A 3)$ with $H A$ $T A T 2$ gene (all strains) or $H A-T A T 2^{5 K>R}$ gene (WT) were grown exponentially in YNB-URA medium and treated with $0,50,75$ and $100 \mathrm{mM}$ APAP for $1 \mathrm{~h}$. Total protein levels were determined by protein assay (Bio-Rad) and equal amounts of protein were loaded. The blots were assayed for HA-Tat2 expression (on the left). $B$-actine expression was used as the loading control (on the right) 
each amino acid without APAP did not have a growth effect on the cells (data not shown). Both WT and trpl $\Delta$ strains exhibited impaired growth in the presence of APAP, but the effect on $\operatorname{trp} 1 \Delta$ cells was much stronger, similar to what was already observed on a solid culture (Fig. 3b). Addition of Trp enhanced growth, especially in the trpl $\Delta$ cells. In contrast, addition of Tyr and Phe increased the APAP-induced toxicity and almost completely inhibited growth (Fig. 4a, b).

Addition of Arg, Lys, Glu and Thr did not have a major effect on growth rate (Fig. 4c, d). In conclusion, these experiments showed that only addition of Trp was sufficient to rescue growth of $\operatorname{trp} 1 \Delta$ upon APAP exposure, while addition of Tyr and Phe increased APAP toxicity leading to an almost complete growth arrest. These results suggest that
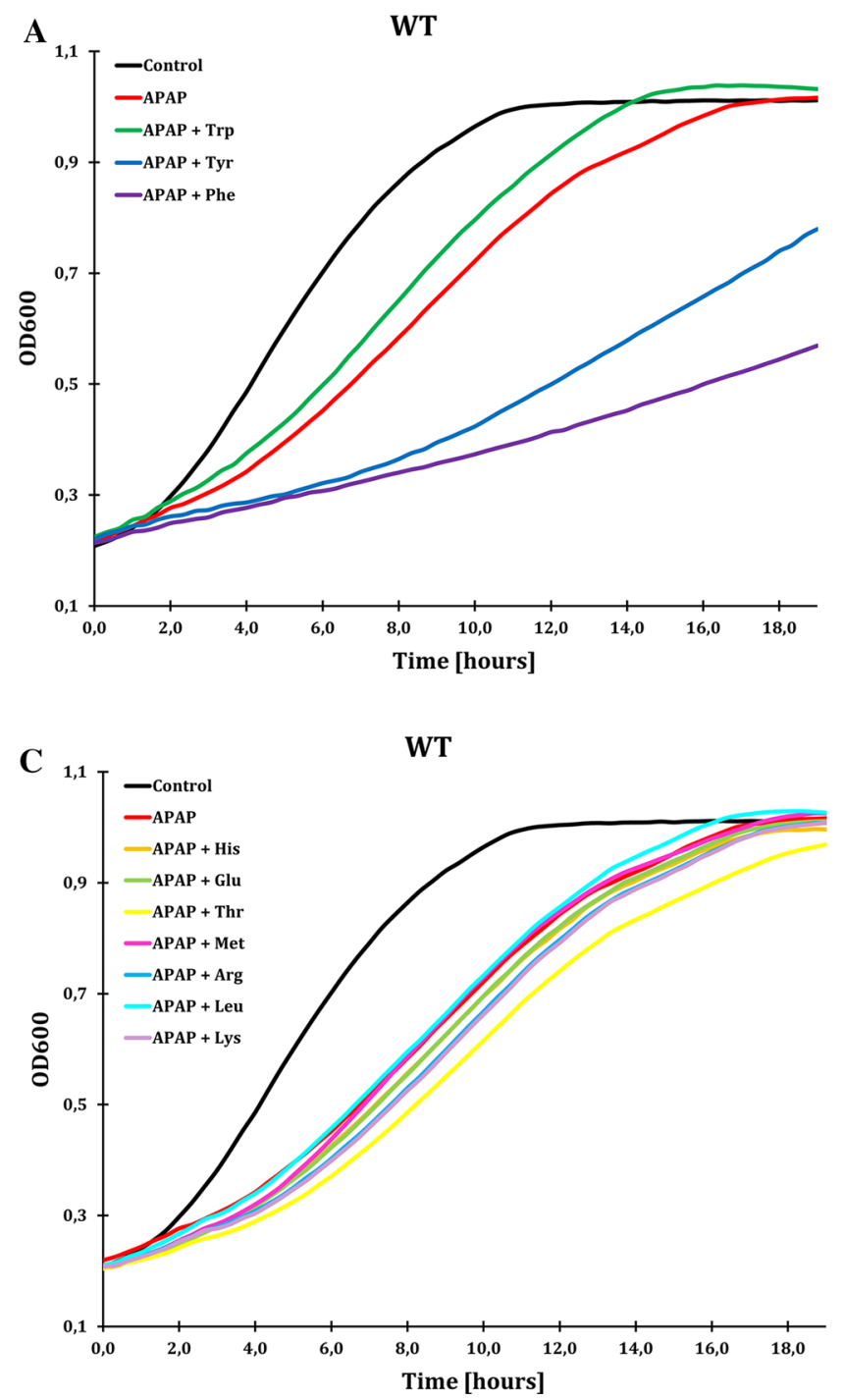

Fig. 4 Effect of amino acids supplements on APAP-induced growth inhibition. The WT and trpls cells were grown in a 96-well in YNB medium and treated with $40 \mathrm{mM}$ APAP with and without onefold addition of single amino acids: $\mathbf{a}$ and $\mathbf{b}$ Trp, Tyr and Phe, and $\mathbf{c}$ and
APAP causes a growth-limiting shortage of intracellular Trp. The raw data and the calculations are presented in Online Resource 1.

\section{The role of Tat1 and Tat2 permeases in APAP sensitivity}

Next, we investigated the relative importance of TAT1 and TAT2. Therefore, we tested the growth effect of addition of Trp, Tyr or Phe on tat $1 \Delta$ and tat $2 \Delta$ strains during APAP exposure. Notably, tat $2 \Delta$ showed similar growth as the WT, with a slight growth rescue upon addition of Trp, and enhanced toxicity after Tyr or Phe addition (Fig. 5b, d). However, tat $1 \Delta$ showed higher sensitivity to APAP, almost

B
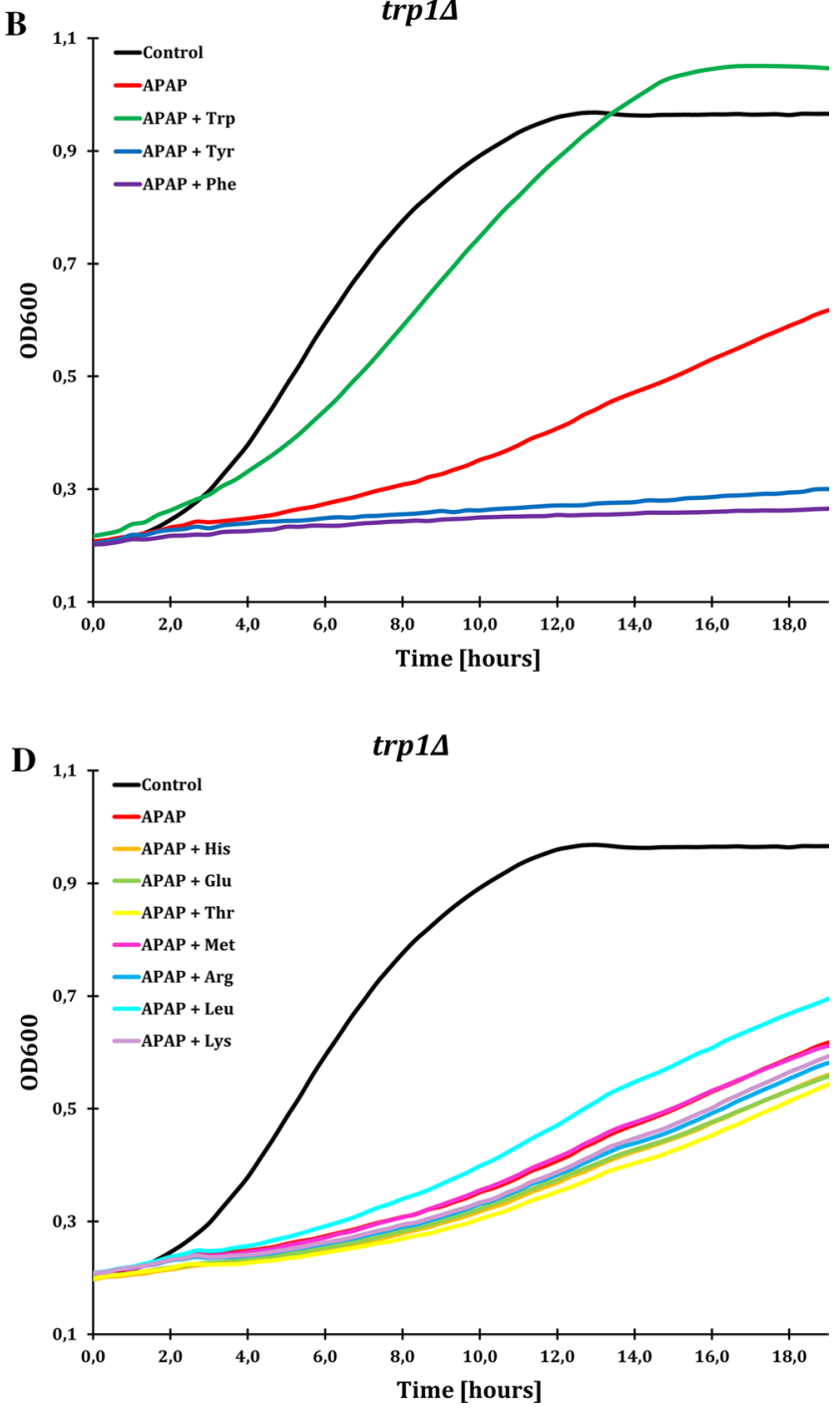

d His, Glu, Thr, Met, Arg, Leu and Lys. $\mathrm{OD}_{600}$ measurements were performed every $20 \mathrm{~min}$ for $19 \mathrm{~h}$. The standard errors from two individual measurements are not presented, but were not higher than 5\% (see Online Resource 1) 
complete growth impairment after addition of Tyr and Phe, but no growth rescue after Trp addition (Fig. 5a) indicating that Tat 1 is the main transporter of Trp into the cells under these conditions. Addition of Glu, Lys and, especially, Met or Thr had a negative growth effect upon APAP exposure in tat $1 \Delta$ (Fig. 6c), suggesting a complex role of Tat1 in maintaining amino acid availability. The raw data and the calculations are presented in Online resource 1.

\section{Changes in intracellular amino acid levels upon APAP treatment}

Our findings that APAP induced the degradation of high affinity permeases (Fig. 1) and that APAP toxicity can be rescued by addition of $\operatorname{Trp}$ (Fig. 4) prompted us to determine the effect

A

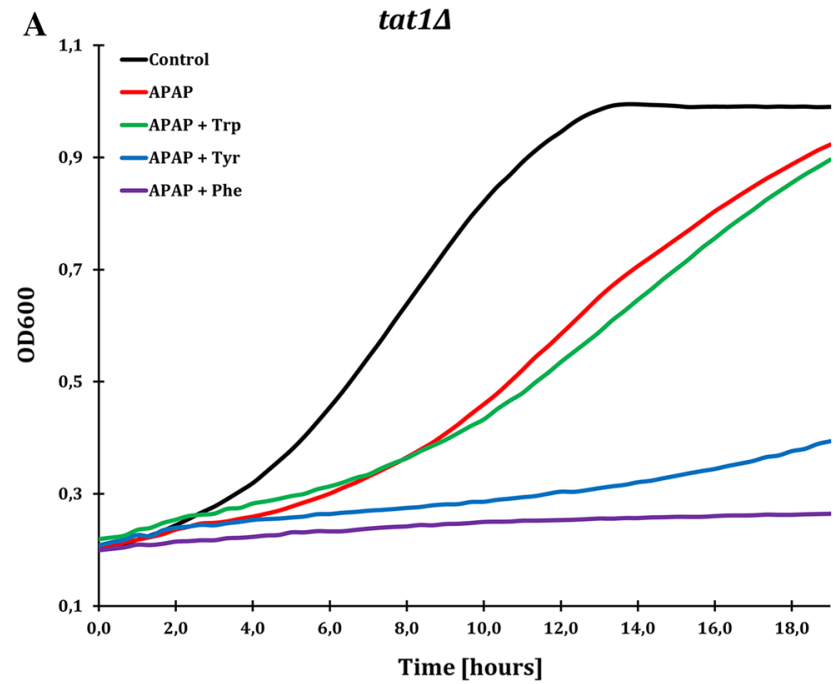

C

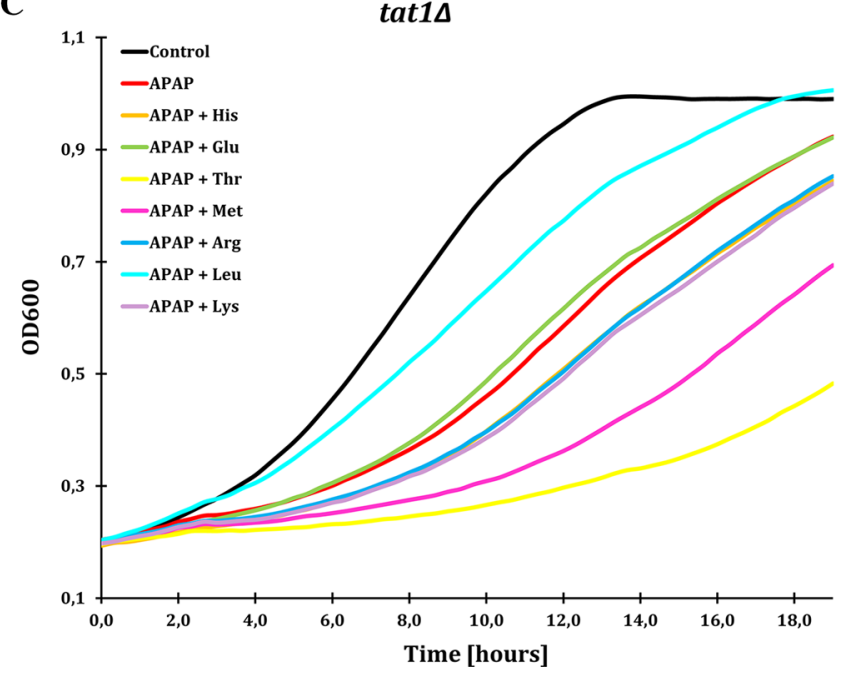

Fig. 5 TAT1 is required for growth rescue by tryptophan upon APAP exposure. The tat1s tat $2 \Delta$ cells were grown in a 96-well plate in YNB medium and treated with $40 \mathrm{mM}$ APAP with and without the addition of onefold of single amino acids: $\mathbf{a}$ and $\mathbf{b}$ Trp, Tyr and Phe, of APAP on intracellular levels of all amino acids. For that purpose, we cultured WT cells in liquid YPD culture in the presence or absence of APAP and harvested after 10, 30 and $60 \mathrm{~min}$. The level of each amino acid upon APAP treatment was determined by HPLC analysis relative to the non-treated cells. The results showed that already after $10 \mathrm{~min}$ of APAP treatment there was a decrease in the intracellular levels of Leu, Met, Phe, Tyr, Arg, Asp, Lys, Trp, and His, while Gly, Gln and Thr showed increased levels (Fig. 6). After $30 \mathrm{~min}$ of APAP treatment, an even higher decrease of most amino acid levels was measured, except for Ile, Ala, Gly, Glu and Gln, while after $60 \mathrm{~min}$ of exposure all amino acid levels were decreased except for Glu, and Gln, which were increased (Fig. 6). Note that we did not present Cys, due to the low levels of detection. It is known, that Cys is a low abundant amino

B

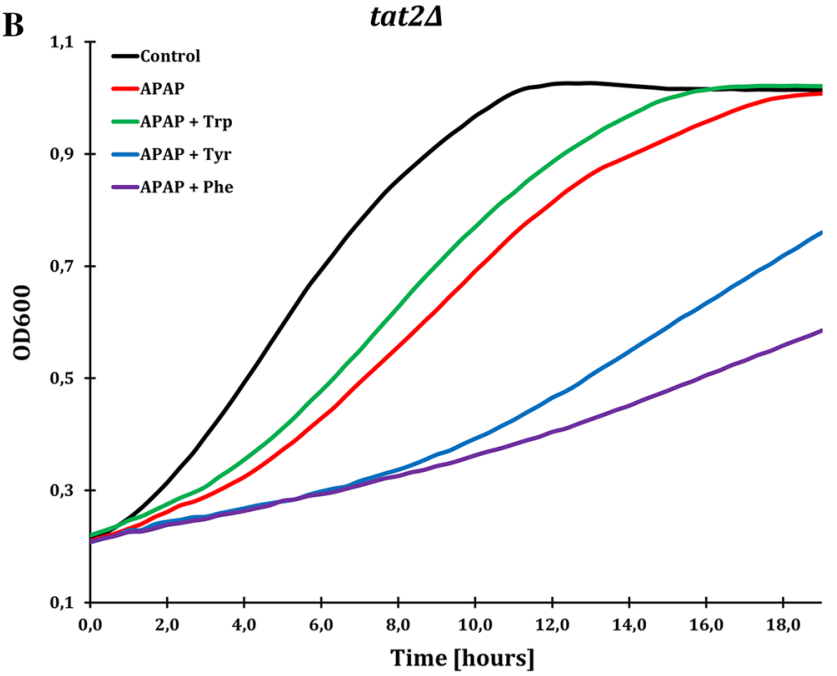

D

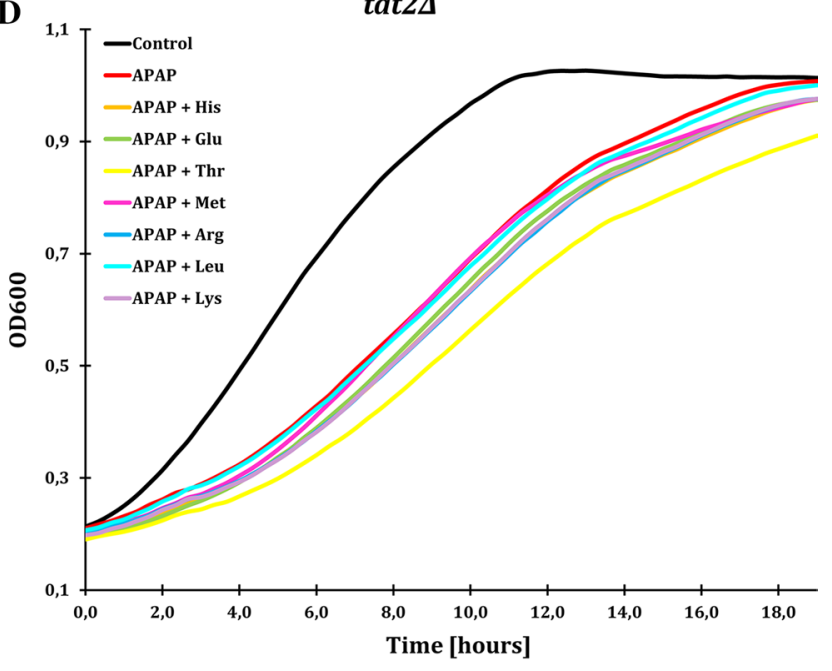

and $\mathbf{c}$ and $\mathbf{d}$ His, Glu, Thr, Met, Arg, Leu and Lys. The $\mathrm{OD}_{600}$ measurements were performed each $20 \mathrm{~min}$ for $19 \mathrm{~h}$. The standard errors from two individual measurements are not presented, but were not higher than 5\% (see Online Resource 1) 


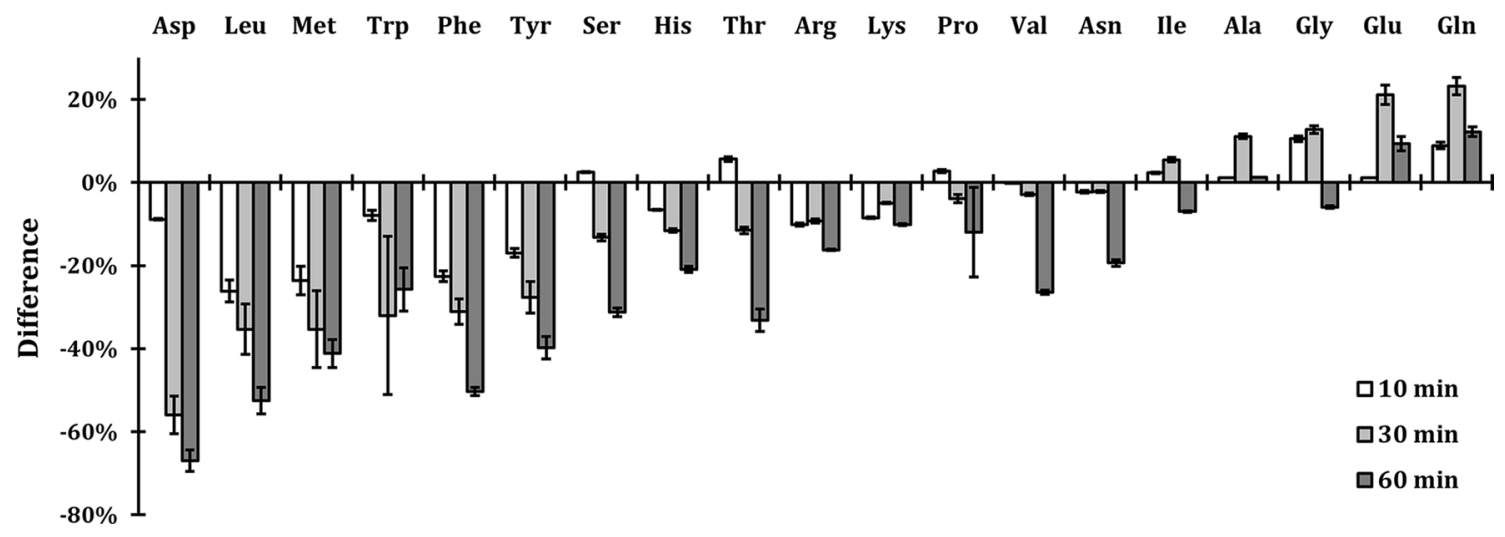

Fig. 6 APAP-induced changes in amino acid levels. WT cells were grown exponentially in YPD medium and treated with $75 \mathrm{mM}$ APAP for 10,30 and $60 \mathrm{~min}$ at $37^{\circ} \mathrm{C}$. The intracellular amino acid levels were measured by HPLC. The bars represent relative increase

acid in yeast (Romagnoli et al. 2015). The complete set of raw data and calculations are presented in Online resource 2.

\section{Differences in amino acid levels between WT and APAP resistant strains}

Since the expression levels of Tat 2 were stable in ubiquitindeficient strains (Fig. 2b) (Miura and Abe 2004), we determined the effect of APAP exposure on the amino acids levels in several of these deletion strains, i.e., ubi4 4 , doa $4 \Delta$ and doa $1 \Delta$. The cells were grown exponentially, exposed to APAP for $1 \mathrm{~h}$ and the intracellular amino acid levels were measured by HPLC (Fig. 7). Most amino acid levels in the ubiquitin-deficient strains were less decreased than in wildtype cells, especially the amino acids Leu, Phe, Met, Tyr, Ser, Val, Trp and Asn. Strains ubi4t and doa $4 \Delta$ showed similar profile of increase/decrease for all amino acid levels, indicating that the APAP resistance of doa $4 \Delta$, similar to $u b i 4 \Delta$, is probably due to the ubiquitin deficiency. In contrast to WT, Gly levels were increased in $u b i 4 \Delta$, doal $\Delta$ and doa $4 \Delta$ upon APAP exposure. Ser and Ala were markedly increased in only $u b i 4 \Delta$ and doa $4 \Delta$. The complete set of raw data and calculations are presented in Online resource 3.

\section{Intracellular amino acid concentration in HepG2 cells upon APAP treatment}

Finally, we compared these findings to the human hepatoma cell line HepG2. We cultured HepG2 cells in the presence of 10 and $20 \mathrm{mM}$ APAP and measured the intracellular amino acid levels by HPLC. Interestingly, the results revealed that, similar to yeast, APAP also induced significant changes in amino acid levels in HepG2 cells in a dose-dependent manner (Fig. 8a, b). The highest decrease was measured for Trp, Met, Leu, Val, Phe, Ile, Tyr and Lys (10 mM APAP), with decrease in intracellular amino acid levels compared to the nontreated cells. The error bars present standard error of two individual measurements. The amino acids were ordered based on the highest decrease at the 30 min time point

an increase in levels of Gly and Glu (Fig. 8a). The decreased amino acids are all essential in human cells (except for Tyr, which is conditionally essential), suggesting that decrease in amino acid levels probably occurred because of impaired uptake. A striking difference was in the levels of Asp, which were highly reduced in yeast and highly increased in human cells. At the concentration of $20 \mathrm{mM}$, all amino acid levels were decreased except for Asp and Glu (Fig. 8b). Note that Cys and Arg were under the detection level in these samples. The raw data and the calculations are presented in Online resource 4.

\section{Discussion}

In our previous research, we made a link between ubiquitin levels and APAP toxicity in yeast (Huseinovic et al. 2017b) and showed, using a DUB deletion strain screen (Huseinovic et al. 2017a), that APAP had a comparable toxicity profile as tyrosine and an overlap with drugs causing internalization of high affinity AAP Tat2 (rapamycin and quinine) (Beck et al. 1999; Khozoie et al. 2009). In this study, we explored these observations further by investigating whether APAP can cause a nutrient starvation response in yeast and alter the intracellular concentration of amino acids.

We showed that APAP caused degradation of high affinity AAPs Tat1, Tat2, Mup1 and Hip1, and upregulation of general AAP Gap1: hallmarks of a nutrient starvation response. Because only overexpression of Tat 1 and Tat2 conferred resistance to APAP, which are both transporters of aromatic amino acids Trp and Tyr, this points to a specific shortage of (an) aromatic amino acid(s), which cannot be provided by Mup1 and Hip1 with an alternative amino acid specificity (methionine and histide, respectively). Why overexpression of the general permease Gap1 is not able 

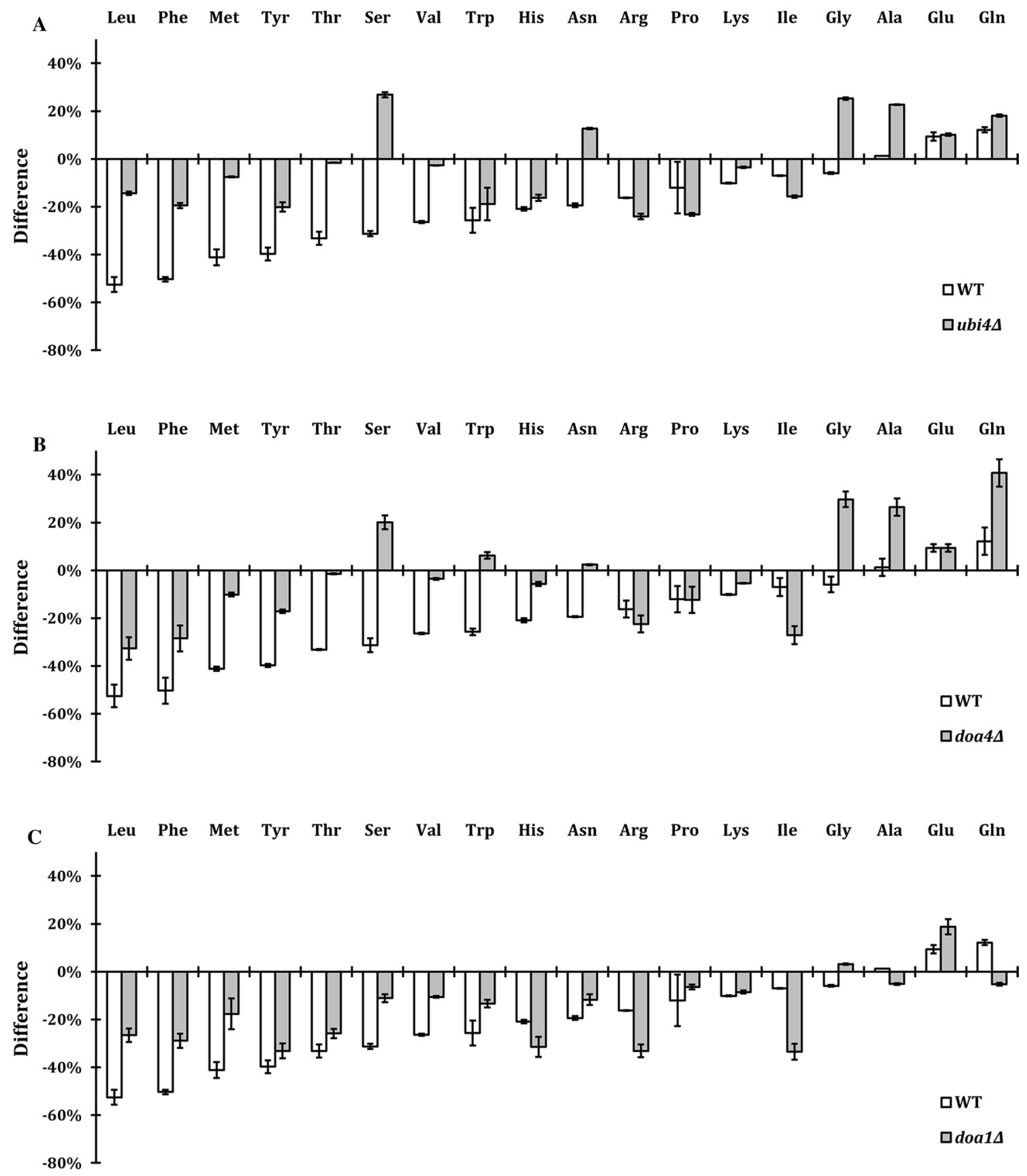

Fig. 7 Relative decrease in amino acid levels upon APAP exposure compared to the wild-type cells is lower in ubiquitin-deficient strains ubi4 $\Delta$, doa $4 \Delta$ and doal $\Delta$. The cells were treated with $75 \mathrm{mM}$ APAP for $1 \mathrm{~h}$ at $37{ }^{\circ} \mathrm{C}$. The values are relative increase/decrease of intracellular levels compared to the non-treated cells. The gray bars represent

to rescue the growth is unclear. A possible explanation is that Gap1 is only expressed during initial nutrient starvation response, but cannot complement for Trp shortage during prolonged incubations in the presence of APAP. Moreover, Tat2 permease was not degraded in the ubiquitin-deficient and APAP resistant strains $u b p 6 \Delta$, doa $4 \Delta$ and $u b i 4 \Delta$ (Fig. 3). Complementation of the medium with individual amino $u b i 4 \Delta \mathbf{a}, \operatorname{doa} 4 \Delta \mathbf{b}$ and $\operatorname{doa} 1 \Delta \mathbf{c}$, and white bars represent WT. The error bars represent the standard error of two independent measurements. The amino acids were ordered based on the highest amino acid level decrease in the WT strain

acids demonstrated that Trp levels were indeed crucial for the growth during APAP exposure, while addition of Tyr and Phe enhanced APAP-induced toxicity. Tyr and Phe enhanced toxicity of APAP, probably due to 1) downregulation of Tat 1 and Tat2 expression and 2) competitive inhibition of Trp import, both leading to a Trp-deficiency. Accordingly, 

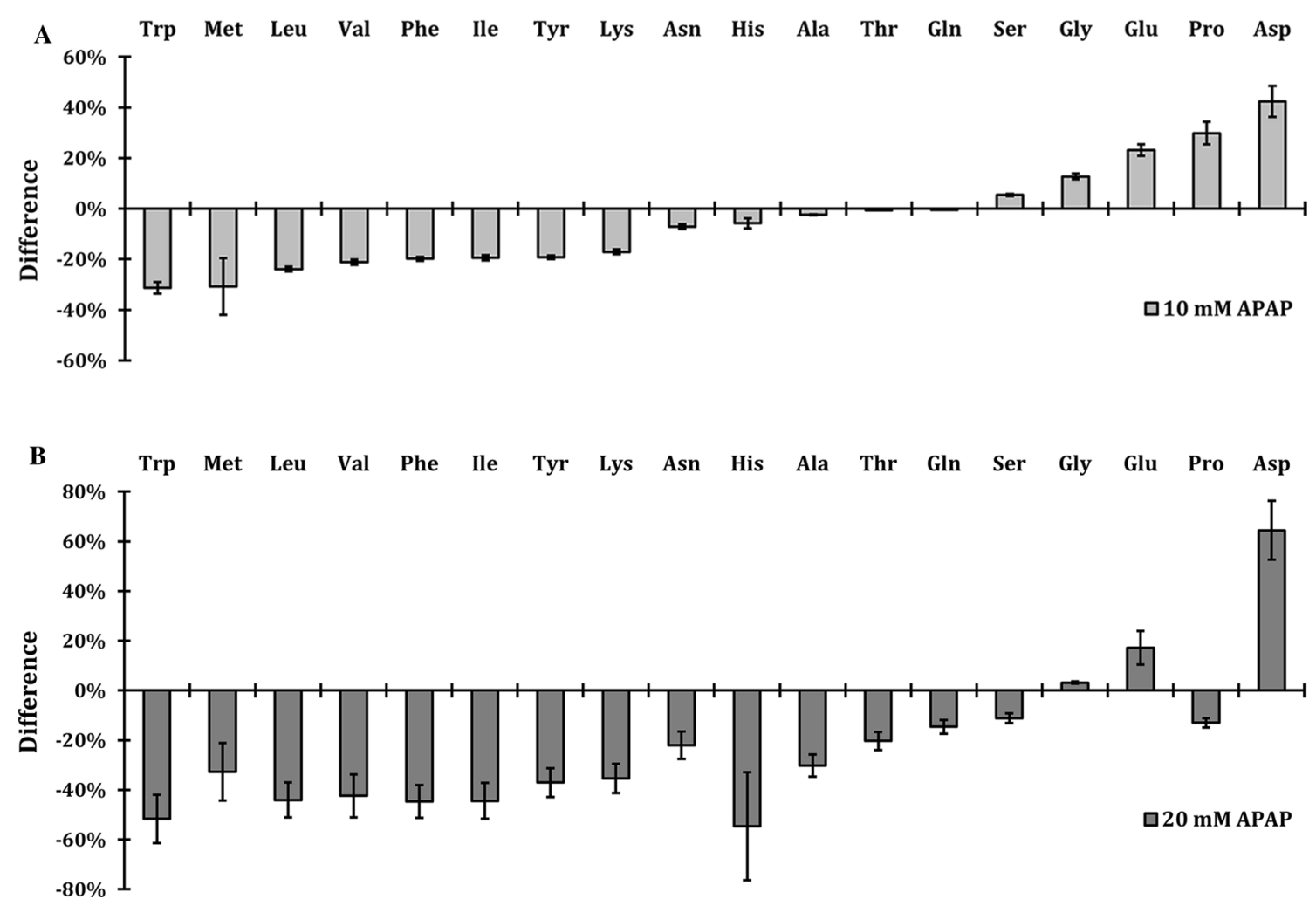

Fig. 8 APAP induces changes in amino acid levels in HepG2 cells. The cells were treated with 10 a and $20 \mathrm{mM}$ APAP for $2 \mathrm{~h} \mathbf{b}$ and intracellular amino acid levels were measured by HPLC. The bars represent relative decrease/increase compared to the non-treated cells.

Trp auxotrophic strain $\operatorname{trp} 1 \Delta$ was hypersensitive to APAP (Fig. 4).

Although overexpression of both Tat 1 and Tat 2 conferred resistance to APAP, only the presence of Tat 1 was crucial for the growth rescue by addition of $\operatorname{Trp}$ and $\operatorname{tat} 1 \Delta$ was more sensitive to APAP than tat $2 \Delta$ (Fig. 5a, b), which had similar growth properties as WT upon APAP exposure (Fig. 4a-d). Moreover, tat $1 \Delta$ strains could only be rescued by addition of Leu, while Trp auxotrophic strain $\operatorname{trpl} 1 \Delta$ showed benefit from addition of Trp and Leu. The importance of Leu and Trp might be explained by the substrate preference of Tat 1 , which transports Leu, Trp, Ile, Val, and Tyr (Schmidt et al. 1994; Regenberg et al. 1999) suggesting that Tat1 is the main transporter of Trp under these conditions. Similar effect is shown for treatment with volatile anesthetic isoflurane in yeast where Tat 1 overexpression also conferred resistance and addition of Trp and Leu rescued growth (Palmer et al. 2002). While WT, trp $1 \Delta$, tat $1 \Delta$ and tat $2 \Delta$ strains were clearly showing growth impairment upon Tyr and Phe addition during APAP treatment, tat $1 \Delta$ also showed impaired growth upon addition of several other amino acids (Met, His, Lys and Thr) suggesting a complex role of Tat1 in regulation of amino acid uptake.
The error bars represent standard error of measurements of two independent biological samples. The amino acids were ordered based on the highest decrease at $10 \mathrm{mM}$ APAP

The consequence of APAP exposure and its induced internalization of AAPs were visualized by quantifying the concentrations of amino acids in both yeast and HepG2 cells. We showed a clear change in intracellular amino acid concentrations upon APAP exposure, which was clearly less in ubiquitin-deficient strains $u b i 4 \Delta$, doa $4 \Delta$ and doal $\Delta$, consistent with the unaffected expression levels of Tat 2 in these strains. Amino acid levels of Leu, Met, Phe, Tyr, Arg, Asp, Lys, Trp and His in WT cells were already decreased after 10 min of APAP treatment, while concentrations of Gln, Gly and Thr were increased. The high decrease in Leu, Met and His may be due to the fact that WT cells are auxotrophic for these amino acids. However, the addition of these amino acids did not rescue the growth during APAP treatment, except for Leu, which had a slight growth rescue in $\operatorname{trpl} \Delta$ strain (Fig. 4d). Accordingly, overexpression of Mup1 (AAP of Met) and Hip1 (AAP of His) also did not rescue the growth indicating further that the depletion of these amino acids was not a primary cause of the nutrient starvation and that their concentrations did not drop below a critical threshold limiting growth. Although yeast is prototrophic for Trp, Phe and Tyr, we measure a high decrease in these amino acid levels probably because they are the most costly 
amino acids to synthetize and cells will preferably rely on uptake to obtain sufficient levels. To synthetize $1 \mathrm{~mol}$ of Trp, Tyr and Phe, 78, 63 and 56 molecules of ATP are needed, respectively (Barton et al. 2010). These three amino acids are also low abundant, especially Trp, which is $5-10$ times less abundant than the next low abundant amino acids (Tyr and Met). This could explain why the levels of Trp are so critical after APAP exposure.

The observed shift to Glu and Gln upon APAP treatment could be explained by the shift from fermentable growth conditions (which yeast undergoes under sufficient nutrient availability) to respiratory growth (which occurs during nutrient starvation). It has been reported that Gly, Ser, Ala, Leu, Val, Tyr, Met, Ile, Thr, and Phe showed the highest concentrations upon fermentable conditions and decreased during a switch to respiratory growth (TCA cycle). Glu reached its highest value under respiratory conditions (Martíezforce and Benítez 1992) and Glu biosynthesis was induced during nutrient starvation response regulated through the retrograde pathway and RTG genes (Johnson et al. 2014). Interestingly, a study with human astrocytes showed that halothane, another volatile anesthetic similar in chemical structure to isoflurane, induced an increase in intracellular Glu (Miyazaki et al. 1997). In our previous study, we showed that deletion of RTG genes RTG1, RTG2, RTG3 and MKS1, conferred resistance to APAP (Huseinovic et al. 2017b).

Finally, we were able to show a similar reduction in amino acid levels in HepG2 cell upon APAP exposure two concentrations: 10 and $20 \mathrm{mM}$, which are often used to study APAP toxicity in human hepatocytes (Utkarsh et al. 2016; Sison-Young et al. 2017). Unlike primary human hepatocytes, HepG2 cells have a very low P450 activity. For comparison, expression levels of CYP2E1 and CYP3A4 (the enzymes mostly involved in APAP metabolism) have been reported to be $\sim 50$-fold and $\sim 200$ fold lower, respectively, in HepG2 cells when compared to human primary hepatocytes (Gerets et al. 2012). We showed a dose-dependent decrease in the intracellular pool of all amino acids except Gly, Glu and Asp. At $10 \mathrm{mM}$ APAP, the highest decrease was measured for Trp, Met, Leu, Val, Phe, Ile, Tyr and Lys. These amino acids are all essential in humans except for Tyr, which is conditionally essential, indicating that it is possibly the uptake inhibition that initially occurs instead of biosynthesis inhibition. In humans, aromatic amino acids Trp, Tyr and Phe are transported by TAT1 transporter expressed in gut endothelial cells and other tissues (Palego et al. 2016). Assuming that the inhibition of Trp by APAP is based on the resemblance of chemical structures of APAP and tyrosine, it is possible that similar inhibition of Trp uptake by APAP could also take place on human aromatic amino acid transporter Tat1. A recently established defective mice $\left(\right.$ tat $\left.^{-/-}\right)$ model (Mariotta et al. 2012) could be used to test its role in APAP toxicity and to see whether addition of different amino acids, especially Trp, Tyr and Phe, would have a similar effect of toxicity as in yeast. Amino acids are precursors of many compounds which are involved in metabolism and neurotransmitters synthesis such as serotonin and melatonin (Trp), dopamine and thyroid hormones (Tyr), Glu which is a neurotransmitter for GABA receptor and many others (Palego et al. 2016). Malnutrition is a high risk for APAP-induced toxicity (Kurtovic and Riordan 2003), which might be linked to reduced nutrient availability upon APAP exposure.

The link between Trp depletion and sensitivity is not only specific for rapamycin (Beck et al. 1999) and APAP, but has been observed for a variety of drugs and conditions such as quinine (Khozoie et al. 2009), ibuprofen (He et al. 2014), immunosuppressors FTY720 (Welsch et al. 2003) and FK560 (Heitman et al. 1993; Schmidt et al. 1994), volatile anesthetics (Palmer et al. 2002) and high pressure (Beck et al. 1999; Palmer et al. 2002; Welsch et al. 2003; Khozoie et al. 2009; He et al. 2014). Inhibition of the TOR pathway (rapamycin) and competitive inhibition of $\operatorname{Trp}$ uptake on amino acid transporters (quinine and ibuprofen) have been described as mechanisms that can induce nutrient starvation.

In conclusion, we showed that APAP in yeast leads to loss of high affinity AAPs and has an effect on amino acid availability. The availability of Trp was important for APAP-induced toxicity and non-toxic additions of Tyr and Phe drastically contributed to the toxicity. Moreover, we were able to translate these findings to human cell line HepG2. Therefore, it would be desirable to investigate whether APAP has an effect on nutrient availability in humans, leading to a better understanding of APAP toxicity.

Acknowledgements This research was supported by AIMMS, the Amsterdam Institute for Molecules, Medicines and Systems, Bridging Ph.D project 10-001-204. SJD was supported by the MIP-DILI project, a European Community grant under the Innovative Medicines Initiative (IMI) Program [115,336]. We kindly thank Michael N. Hall (Biozentrum, University of Basel, Switzerland) and Jan Paul Bebelman (Medicinal Chemistry, VU Amsterdam) for providing plasmids. We thank Dr. Fred van Leeuwen (Netherlands Cancer Institute, Amsterdam) and our internship students Sanjay Nannan Panday, Ellen Vonk and Anna Huguet Ninou for their valuable contribution to the project.

\section{Compliance with ethical standards}

Conflict of interest The authors declare that they have no conflict of interests regarding the publication of this paper.

Open Access This article is distributed under the terms of the Creative Commons Attribution 4.0 International License (http://creativeco mmons.org/licenses/by/4.0/), which permits unrestricted use, distribution, and reproduction in any medium, provided you give appropriate 
credit to the original author(s) and the source, provide a link to the Creative Commons license, and indicate if changes were made.

\section{References}

Abe F, Iida H (2003) Pressure-induced differential regulation of the two tryptophan permeases Tat 1 and Tat 2 by ubiquitin ligase Rsp5 and its binding proteins, Bul1 and Bul2. Mol Cell Biol 23:7566-7584

Alaiz M, Navarro JL, Girón J, Vioque E (1992) Amino acid analysis by high-performance liquid chromatography after derivatization with diethyl ethoxymethylenemalonate. J Chromatogr 591:181-186

Barton MD, Delneri D, Oliver SG et al (2010) Evolutionary Systems Biology of Amino Acid Biosynthetic Cost in Yeast. PLoS One 5:e11935. https://doi.org/10.1371/journal.pone.0011935

Beck T, Schmidt A, Hall MN (1999) Starvation induces vacuolar targeting and degradation of the tryptophan permease in yeast. J Cell Biol 146:1227-1238

Bernal W, Auzinger G, Dhawan A, Wendon J (2010) Acute liver failure. Lancet 376:190-201. https://doi.org/10.1016/S0140 $-6736(10) 60274-7$

Bessems JGM, Vermeulen NPE (2001) Paracetamol (acetaminophen)-Induced toxicity: molecular and biochemical mechanisms, analogues and protective approaches. Crit Rev Toxicol 31:55-138. https://doi.org/10.1080/20014091111677

Finley D, Ulrich HD, Sommer T, Kaiser P (2012) The ubiquitinproteasome system of Saccharomyces cerevisiae. Genetics 192:319-360. https://doi.org/10.1534/genetics.112.140467

Gerets HHJ, Tilmant K, Gerin B et al (2012) Characterization of primary human hepatocytes, HepG2 cells, and HepaRG cells at the mRNA level and CYP activity in response to inducers and their predictivity for the detection of human hepatotoxins. Cell Biol Toxicol 28:69-87. https://doi.org/10.1007/s10565-011-9208-4

He C, Tsuchiyama SK, Nguyen QT et al (2014) Enhanced longevity by ibuprofen, conserved in multiple species, occurs in yeast through inhibition of tryptophan import. PLoS Genet 10:e1004860. https://doi.org/10.1371/journal.pgen.1004860

Heitman J, Koller A, Kunz J et al (1993) The immunosuppressant FK506 inhibits amino acid import in Saccharomyces cerevisiae. Mol Cell Biol 13:5010-5019

Henderson AJ, Shaheen SO (2013) Acetaminophen and asthma. Paediatr Respir Rev 14:9-15. https://doi.org/10.1016/j. prrv.2012.04.004 (quiz 16)

Huseinovic A, van Dijk M, Vermeulen NPE et al (2017a) Drug toxicity profiling of a Saccharomyces cerevisiae deubiquitinase deletion panel shows that acetaminophen mimics tyrosine. Toxicol In Vitro 47:259-268. https://doi.org/10.1016/j.tiv.2017.12.007

Huseinovic A, van Leeuwen JS, van Welsem T et al (2017b) The effect of acetaminophen on ubiquitin homeostasis in Saccharomyces cerevisiae. PLoS One 12:e173573. https://doi. org/10.1371/journal.pone.0173573

James LP, Mayeux PR, Hinson JA (2003) Acetaminophen-induced hepatotoxicity. Drug Metab Dispos 31:1499-1506. https://doi. org/10.1124/dmd.31.12.1499

Jensen KG, Poulsen HE, Doehmer J, Loft S (1996) Paracetamolinduced spindle disturbances in V79 cells with and without expression of human CYP1A2. Pharmacol Toxicol 78:224-228

Johnson MA, Vidoni S, Durigon R et al (2014) Amino acid starvation has opposite effects on mitochondrial and cytosolic protein synthesis. PLoS One 9:e93597. https://doi.org/10.1371/journ al.pone.0093597

Khawaja A, Shahab A, Hussain SA (2012) Acetaminophen induced Steven Johnson syndrome-toxic epidermal necrolysis overlap. J Pak Med Assoc 62:524-527
Khozoie C, Pleass RJ, Avery SV (2009) The antimalarial drug quinine disrupts Tat2p-mediated tryptophan transport and causes tryptophan starvation. J Biol Chem 284:17968-17974. https:// doi.org/10.1074/jbc.M109.005843

Kim E-J, Lim H, Park SY et al (2014) Rapid onset of Stevens-Johnson syndrome and toxic epidermal necrolysis after ingestion of acetaminophen. Asia Pac Allergy 4:68-72. https://doi.org/10.5415/ apallergy.2014.4.1.68

Klebe RJ, Harriss JV, Sharp ZD, Douglas MG (1983) A general method for polyethylene-glycol-induced genetic transformation of bacteria and yeast. Gene 25:333-341

Kurtovic J, Riordan S (2003) Paracetamol-induced hepatotoxicity at recommended dosage. J Intern Med. https://doi.org/10.104 6/j.1365-2796.2003.01097.x

Larson AM, Polson J, Fontana RJ et al (2005) Acetaminophen-induced acute liver failure: results of a United States multicenter, prospective study. Hepatology 42:1364-1372. https://doi.org/10.1002/ hep. 20948

Liew Z, Ritz B, Rebordosa C et al (2014) Acetaminophen use during pregnancy, behavioral problems, and hyperkinetic disorders. JAMA Pediatr 168:313-320. https://doi.org/10.1001/jamapediat rics.2013.4914

Ljungdahl PO (2009) Amino-acid-induced signalling via the SPSsensing pathway in yeast. Biochem Soc Trans 37:242-247. https ://doi.org/10.1042/BST0370242

Ljungdahl PO, Daignan-Fornier B (2012) Regulation of amino acid, nucleotide, and phosphate metabolism in Saccharomyces cerevisiae. Genetics 190:885-929. https://doi.org/10.1534/genet ics.111.133306

Mariotta L, Ramadan T, Singer D et al (2012) T-type amino acid transporter TAT1 (Slc16a10) is essential for extracellular aromatic amino acid homeostasis control. J Physiol 590:6413-6424. https ://doi.org/10.1113/jphysiol.2012.239574

Martíez-force E, Benítez T (1992) Changes in yeast amino acid pool with respiratory versus fermentative metabolism. Biotechnol Bioeng 40:643-649. https://doi.org/10.1002/bit.260400602

Michaut A, Moreau C, Robin M-A, Fromenty B (2014) Acetaminophen-induced liver injury in obesity and nonalcoholic fatty liver disease. Liver Int 34:e171-e179. https://doi.org/10.1111/liv.12514

Miettinen TP, Björklund M (2014) NQO2 is a reactive oxygen species generating off-target for acetaminophen. Mol Pharm 11:43954404. https://doi.org/10.1021/mp5004866

Miura T, Abe F (2004) Multiple ubiquitin-specific protease genes are involved in degradation of yeast tryptophan permease Tat2 at high pressure. FEMS Microbiol Lett 239:171-179. https://doi. org/10.1016/j.femsle.2004.08.035

Miyazaki H, Nakamura Y, Arai T, Kataoka K (1997) Increase of glutamate uptake in astrocytes: a possible mechanism of action of volatile anesthetics $\mid r 1113$. Anesthesiology 86:1359-1366. https ://doi.org/10.1097/00000542-199706000-00018

Nikko E, Pelham HRB (2009) Arrestin-mediated endocytosis of yeast plasma membrane transporters. Traffic 10:1856-1867. https://doi. org/10.1111/j.1600-0854.2009.00990.x

Palego L, Betti L, Rossi A, Giannaccini G (2016) Tryptophan biochemistry: structural, nutritional, metabolic, and medical aspects in humans. J Amino Acids 2016:8952520. https://doi. org/10.1155/2016/8952520

Palmer LK, Wolfe D, Keeley JL, Keil RL (2002) Volatile anesthetics affect nutrient availability in yeast. Genetics $161: 563-574$

Regenberg B, Düring-Olsen L, Kielland-Brandt MC, Holmberg S (1999) Substrate specificity and gene expression of the amino-acid permeases in Saccharomyces cerevisiae. Curr Genet 36:317-328

Romagnoli G, Knijnenburg TA, Liti G, Louis EJ, Pronk JT, Daran JM (2015) Deletion of the Saccharomyces cerevisiae ARO8 gene, encoding an aromatic amino acid transaminase, enhances 
phenylethanol production from glucose. Yeast 32(1):29-45. https ://doi.org/10.1002/yea.3015

Schmidt A, Hall MN, Koller A (1994) Two FK506 resistance-conferring genes in Saccharomyces cerevisiae, TAT1 and TAT2, encode amino acid permeases mediating tyrosine and tryptophan uptake. Mol Cell Biol 14:6597-6606

Shin C-S, Kim SY, Huh W-K (2009) TORC1 controls degradation of the transcription factor Stp1, a key effector of the SPS amino-acid-sensing pathway in Saccharomyces cerevisiae. J Cell Sci 122:2089-2099. https://doi.org/10.1242/jcs.047191

Shuhendler AJ, Pu K, Cui L et al (2014) Real-time imaging of oxidative and nitrosative stress in the liver of live animals for drug-toxicity testing. Nat Biotechnol 32:373-380. https://doi.org/10.1038/ nbt. 2838

Sison-Young RL, Lauschke VM, Johann E et al (2017) A multicenter assessment of single-cell models aligned to standard measures of cell health for prediction of acute hepatotoxicity. Arch Toxicol 91:1385-1400. https://doi.org/10.1007/s00204-016-1745-4

Srikanth CV, Chakraborti AK, Bachhawat AK (2005) Acetaminophen toxicity and resistance in the yeast Saccharomyces cerevisiae. Microbiology 151:99-111. https://doi.org/10.1099/mic.0.27374-0

Suzuki A, Mochizuki T, Uemura S et al (2013) Pressure-induced endocytic degradation of the Saccharomyces cerevisiae low-affinity tryptophan permease Tat 1 is mediated by Rsp5 ubiquitin ligase and functionally redundant PPxY motif proteins. Eukaryot Cell 12:990-997. https://doi.org/10.1128/EC.00049-13

Utkarsh D, Loretz C, Li AP (2016) In vitro evaluation of hepatotoxic drugs in human hepatocytes from multiple donors: identification of P450 activity as a potential risk factor for drug-induced liver injuries. Chem Biol Interact 255:12-22. https://doi.org/10.1016/j. cbi.2015.12.013

Walter RB, Brasky TM, White E (2011a) Cancer risk associated with long-term use of acetaminophen in the prospective VITamins and lifestyle (VITAL) study. Cancer Epidemiol Biomarkers Prev 20:2637-2641. https://doi.org/10.1158/1055-9965.EPI-11-0709

Walter RB, Milano F, Brasky TM, White E (2011b) Long-term use of acetaminophen, aspirin, and other nonsteroidal anti-inflammatory drugs and risk of hematologic malignancies: results from the prospective vitamins and lifestyle (VITAL) study. J Clin Oncol 29:2424-2431. https://doi.org/10.1200/JCO.2011.34.6346

Welsch Ca, Hagiwara S, Goetschy JF, Movva NR (2003) Ubiquitin pathway proteins influence the mechanism of action of the novel immunosuppressive drug FTY720 in Saccharomyces cerevisiae. J Biol Chem 278:26976-26982. https://doi.org/10.1074/jbc.m2131 44200 